\title{
Depressão melancólica e depressão atípica: aspectos clínicos e psicodinâmicos
}

\author{
Melancolic depression and atypic depression: \\ clinical and psychodynamic aspects
}

\author{
Evandro GOMES DE MATOS \\ Thania Mello GOMES DE MATOS ${ }^{2}$ \\ Gustavo Mello GOMES DE MATOS
}

\begin{abstract}
Resumo
O objetivo deste estudo foi revisar a epidemiologia, a sintomatologia clínica e a classificação dos diversos subtipos de transtornos depressivos, conforme os modernos sistemas de diagnóstico e de pesquisa, e descrever, de forma crítica, sob à luz da Psicanálise, os principais aspectos psicodinâmicos subjacentes. Destacamos, particularmente, os quadros de depressão melancólica e atípica, enfatizando a necessidade do reconhecimento diagnóstico precoce e da compreensão psicanalítica como instrumentos importantes para a intervenção e para o tratamento.
\end{abstract}

Palavras-chave: depressão atípica; depressão melancólica; psicanálise.

\begin{abstract}
The aim of this paper was to review the epidemiology, symptomatology and classification of depressive disorders according to the modern systems diagnosis and research. This study had also the objective to describe, throughout the psychoanalysis theory, the depressive disorders main aspects, specially the melancholic and the atipic features. All along the text it has been emphasized the importance of an early diagnosis combined to a psychoanalytical comprehension of the patient's condition.
\end{abstract}

Key words: atypical depression; melancholic depression; psychoanalysis.

A depressão é um dos transtornos mentais mais freqüentes na população geral. Ocorre em todas as faixas etárias, sendo responsável por altos custos de tratamento, diretos e indiretos, e produzindo grandes prejuízos para o indivíduo e para a sociedade devido à sua natureza crônica, alta morbidade e mortalidade
(Greenberg, Stiglin \& Finkelstein, 1993a; Murray \& Lopez, 1996; Pincus \& Pettit, 2001).

Tem havido, ultimamente, um crescente aumento do número de casos em todo o mundo, motivo pelo qual a depressão vem sendo considerada uma verdadeira epidemia. A Organização Mundial da

$\boldsymbol{M} \boldsymbol{\nabla V}$

1 Professor Doutor, Departamento de Psicologia Médica e Psiquiatria, Faculdade de Ciências Médicas, Universidade Estadual de Campinas. Cidade Universitária Zeferino Vaz, Barão Geraldo, 13086-970, Campinas, SP, Brasil. Correspondência para/Correspondence to: E.G. MATOS. E-mail: <evandro@fcm.unicamp.br>.

2 Mestre, Psicóloga Clínica, Clínica Gomes de Matos. Campinas, SP, Brasil.

3 Acadêmico, Faculdade de Medicina, Universidade de Uberaba. Uberada, MG, Brasil. 
Saúde (OMS) e a Associação Psiquiátrica Americana (APA) estão desenvolvendo esforços para aprimorar os métodos diagnósticos de todos os profissionais da área da saúde a fim de detectar e prevenir o aparecimento de novos casos, bem como incrementar estratégias eficazes de tratamento. Apesar disso, estima-se que na maioria das vezes o transtorno depressivo não seja diagnosticado e tratado - mesmo nos países de primeiro mundo -, comprometendo a qualidade de vida desses pacientes em decorrência da cronificação e das complicações inerentes ao quadro (Birmaher, Ryan \& Williamson, 1996; Greenberg, Stiglin \& Finkelstein, 1993b).

As complicações descritas com maior freqüência são: o abuso do álcool e outras substâncias, as tentativas de suicídio, o suicídio, e o desenvolvimento de doenças correlatas, como o diabetes, o infarto do miocárdio e os distúrbios vasculares (Regier, Narrow \& Rae, 1993).

O objetivo deste artigo é fazer uma breve descrição sobre o assunto, abordando os critérios diagnósticos, a prevalência e os subtipos de depressão, segundo os modernos sistemas de classificação - Classificação Internacional de Doenças Mentais (CID-10), da OMS, e Manual Diagnóstico e Estatístico dos Transtornos Mentais (DSM-IV), da APA - e discutir os mecanismos psicodinâmicos subjacentes, observados sob à luz desses conhecimentos clínicos atuais.

\section{Diagnóstico}

Um episódio depressivo se caracteriza por um período de duração mínimo de duas semanas, com a presença de dois grupamentos de sintomas: 1) humor triste, diminuição do interesse e do prazer, diminuição da energia e fatigabilidade; e 2) pessimismo, diminuição da auto-estima, ideação de ruína e/ou culpa, pensamentos e atos suicidas, diminuição ou aumento do apetite, diminuição ou aumento do sono, diminuição da atenção e concentração, alteração da atividade psicomotora, lentificação ou agitação. Classifica-se o episódio depressivo em três níveis: leve, quando estão presentes dois sintomas do primeiro grupamento e dois ou três do segundo; moderado, quando presentes dois do primeiro e três ou quatro do segundo, e grave, quando presentes três do primeiro e quatro ou mais do segundo (CID-10, 1990). A importância dessa classi- ficação é fornecer subsídios para pesquisa, facilitar a comunicação entre os profissionais e auxiliar a tomada de decisão do tratamento.

Por via de regra indica-se psicoterapia para os casos leves, psicoterapia e/ou tratamento farmacológico para os casos moderados e graves. Nesses últimos, há de se considerar a necessidade de internação, especialmente quando existe risco de suicídio (Davidson \& Meltzer-Brody, 1999; Friedman \& Kocsis, 1996; Kocsis, 2000). São também considerados graves aqueles episódios acompanhados de sintomas catatônicos ou psicóticos, alucinações e delírios. Recomenda-se identificar se os delírios são congruentes com o humor, por exemplo, delírios de culpa ou de ruína, ou incongruentes com o humor, por exemplo, delírios de grandeza ou persecutórios (DSM-IV, 1995).

Quando o episódio depressivo se repete uma ou mais vezes, denominamos o quadro de Transtorno Depressivo Recorrente. Se os episódios subseqüentes forem sempre episódios depressivos, são denominados de Transtorno Depressivo Unipolar e se houver um ou mais episódios intercalados de mania ou hipomania - independente da ordem de surgimento -, denominamos o quadro de Transtorno Bipolar do Humor (DSM-IV) ou Transtorno Afetivo Bipolar (CID-10).

\section{Epidemiologia}

Estudos epidemiológicos recentes têm demonstrado um aumento de casos de depressão nas diversas faixas etárias em todo o mundo. Entretanto, não se conhece a causa - ou causas - desse fenômeno. É possível que os médicos estejam mais capacitados para reconhecer e diagnosticar o transtorno. Além disso, a informação científica está mais disponível ao público, aumentando a procura por ajuda. Por outro lado, a expectativa de vida aumentou, crescendo também a chance do aparecimento de casos de início tardio. Especula-se, também, o envolvimento de fatores genéticos hereditários que, por alguma razão, estariam aumentando nos últimos anos.

Do ponto de vista cultural vivemos uma época de mudanças rápidas nos valores e costumes. O stress oriundo dessas mudanças, a competição pela sobrevivência, o desemprego, a corrupção dos políticos, o jogo, a dissolução dos laços familiares, o abandono 
das crenças e práticas religiosas, a violência urbana, o caos do trânsito, a promiscuidade sexual, o abuso de álcool e drogas têm sido apontados, repetidas vezes, como fatores facilitadores da depressão (Frank, Prien \& Jarret, 1991).

No Brasil, não temos estudos epidemiológicos abrangentes, mas admite-se que a nossa realidade não seja diferente dos países de primeiro mundo. Nos Estados Unidos, destacam-se dois estudos: o Epidemiologic Catchment Area Survey (ECA), conduzido pelo National Institute of Mental Health - com 18 mil indivíduos, em cinco cidades americanas -, que apontou uma taxa de prevalência aproximada de 5,0\% para a população geral, no momento atual, e uma expectativa de 17,0\%, ao longo da vida (Kessler, Burns \& Shapiro, 1987) - e a pesquisa do National Comorbidity Survey (NCS) - realizada com cerca de 8 mil indivíduos de diversos estados americanos que apontou uma prevalência de 4,9\%, no momento atual, e de 17,7\%, ao longo da vida (Kessler, McConagle \&Zhoa, 1994).

Segundo o NCS a idade média de início é de 20 anos e a relação mulher/homem é de 1:2, aproximadamente. Um episódio típico não tratado tem uma duração média de seis meses. A possibilidade da ocorrência de episódios subseqüentes aumenta com o número de episódios. Após o primeiro é de $50 \%$, após o segundo, de $70 \%$ e após o terceiro, de $90 \%$. As chances de suicídio giram em torno de 15\% dos casos. Por isso, há a necessidade da realização de um diagnóstico precoce, que permita uma rápida intervenção terapêutica, visando abortar os sintomas depressivos, bem como prevenir as recaídas (Gomes de Matos, 1999).

\section{Subtipos de depressão (DSM - IV)}

\section{Critérios diagnósticos}

- Transtorno depressivo maior: durante um período mínimo de duas semanas ocorrem cinco dos sintomas abaixo, entre os quais necessariamente deverão estar presentes pelo menos a ou b, como segue: a) humor depressivo, relatado pelo próprio indivíduo ou observado por outros, ou b) perda do interesse ou prazer por atividades que são habitualmente prazerosas, referida pelo indivíduo ou observada por outros; c) perda ou aumento de apetite, com diminuição ou ganho de peso corporal, d) insônia ou hipersonia em quase todos os dias, e) diminuição ou aumento da atividade psicomotora, presente não apenas no relato do indivíduo, mas também observado por outros, f) diminuição da disposição e da energia, quase todos os dias, g) dificuldade de concentração e de tomar decisões, h) comportamento suicida caracterizado por ideação recorrente, planos ou tentativas de suicídio.

Os sintomas causam sofrimento considerável, ou prejuízo funcional. Eles não são desencadeados por luto e nem são o resultado da ação direta do uso de substâncias, ou de uma condição clínica, por exemplo, hipotireoidismo.

- Distimia (Transtorno distímico): humor deprimido na maior parte do dia, na maioria dos dias, por um período de pelo menos dois anos (no adolescente apenas um ano), acompanhado de dois ou mais dos seguintes sintomas: apetite diminuído ou aumentado, insônia ou hipersonia, diminuição da energia e fadiga, baixa da auto-estima, diminuição da concentração e da capacidade de tomada de decisões.

Não se faz o diagnóstico quando o quadro decorre do uso direto de substâncias, ou é explicado por uma condição médica geral, e quando um quadro psiquiátrico mais grave ocorre simultaneamente, como esquizofrenia, transtorno bipolar do humor ou transtorno delirante.

- Transtorno depressivo com características melancólicas: durante um episódio depressivo maior ocorrem quatro dos seguintes sintomas, dentre os quais necessariamente estarão presentes a ou b, como segue: a) perda do prazer por quase todas as atividades, b) ausência de reatividade aos estímulos agradáveis, c) relato de uma qualidade distinta do humor depressivo, d) humor deprimido sendo mais intenso pela manhã, e) despertar na madrugada (insônia tardia), f) retardo psicomotor ou agitação psicomotora, g) perda significativa do apetite e do peso corporal, h) culpa excessiva.

- Transtorno depressivo com características atípicas: pode ocorrer tanto no episódio depressivo maior quanto na distimia. Deverá haver, necessariamente, a presença de reatividade do humor, isto é, o humor melhora com estímulos agradáveis e pelo menos dois dos sintomas que seguem devem estar presentes: ganho de peso ou aumento significativo do 
apetite; hipersonia; sensação de peso no corpo, especialmente nos membros (paralisia de chumbo); sensibilidade à rejeição interpessoal, que se mantém mesmo fora dos períodos de depressão, como uma característica da personalidade que causa prejuízo social ou ocupacional significativo.

\section{Mecanismos psicodinâmicos da depressão}

Freud, em 1917, em sua obra "Luto e Melancolia", descreve e diferencia, pela primeira vez, os aspectos psicodinâmicos dos sintomas depressivos que ocorrem no luto e na melancolia (Freud, 1917/1972b). O luto é uma reação normal, de ocorrência esperada, no sujeito que perdeu um objeto amado, um ente querido, ou que sofre pela perda de alguma coisa abstrata, que ocupou o lugar do ente querido, como a liberdade ou os seus ideais.

O vínculo com o objeto amado é representado por centenas de recordações, que são dolorosas, no primeiro instante, mas que vão ganhando uma tonalidade de doce saudade, com o passar do tempo. A solução de cada recordação se dá em separado e demanda períodos de tempo diferentes. Esse é o trabalho do luto, expressão utilizada por Freud, que é de execução difícil e desagradável. Consiste basicamente num primeiro movimento ambivalente, de introjeção do objeto perdido, e num segundo que busca facilitar o afrouxamento final. A ilusão de que a pessoa morta ainda sobrevive é um dos mecanismos do luto, que persiste durante algum tempo, e está ligado ao processo de identificação. Isso pode ser observado, particularmente, quando o indivíduo busca se assemelhar, nas atitudes, com o objeto perdido. Passa a agir e se portar como se fora o outro, assumindo inconscientemente os mesmos atos e posturas em relação às qualidades consideradas boas. Outras vezes, adotam-se posturas de identificação claramente conscientes, por exemplo: "como meu pai se comportaria frente a este fato se ainda fosse vivo"?, ou "meu pai, se estivesse vivo, estaria orgulhoso de meu sucesso profissional". Esse trabalho, em última análise, visa erigir internamente um objeto substituto. Ao término da elaboração de luto considera-se que o ego está livre outra vez e desimpedido.

Na melancolia - estado que hoje denominamos depressão -, Freud distinguiu os seguintes aspectos: desânimo profundo, cessação do interesse para o mundo externo, perda da capacidade de amar, inibição de toda a atividade e diminuição dos sentimentos de auto-estima. Um componente constitucional deve contribuir para a formação dos sintomas, porque as mesmas causas podem produzir luto em alguns indivíduos e, noutros, melancolia. Nessa última, a pessoa tenta anular a perda, mas a agrava pela introjeção, que é o mecanismo psíquico usado para instalar o objeto dentro de seu próprio ego. Entretanto, ao perder o objeto amado, o sujeito pode estar consciente de quem ele perdeu, mas não tem notícia do que ele perdeu.

O conceito de introjeção nos reporta ao exame da natureza da identificação, que está relacionada com a fase canibalística. Freud faz uma ligação entre a depressão e a fase oral do desenvolvimento, porque a introjeção decorre da incorporação oral do objeto perdido, que havia sido previamente eleito por meio da escolha narcísica objetal, isto é, escolhido pelo modelo do próprio ego. Assim, a introjeção sádico-oral do objeto - cujo amor se quer como provisão narcísica -, é o estopim que faz eclodir a necessidade narcísica, reprimida e ambivalente, do objeto amado.

Existem três modalidades de identificação (Laplanche \& Pontalis, 1986): a identificação primária, que é o modo primitivo da constituição do indivíduo, segundo o modelo do outro e que engloba os conceitos de imitação, empatia, simpatia, contágio mental etc.; a identificação como um substituto regressivo de uma escolha de objeto abandonado; identificação com elementos comuns, por exemplo, o desejo de ser amado.

Na depressão melancólica predomina o segundo modelo de identificação, o de substituto regressivo, e a expressão do quadro pode incluir sintomas psicóticos. Na depressão atípica predominam os mecanismos de deslocamento, do terceiro modelo de identificação, que tornam o quadro mais próximo das neuroses, como veremos abaixo.

\section{Mecanismos psicodinâmicos na depressão melancólica}

O quadro da depressão melancólica vem acompanhado por ideação de suicídio, pelas idéias de culpa e de ruína, e pelas distorções sensoperceptivas corporais e da realidade externa. A incorporação e a 
introjeção são os protótipos da identificação que ocorrem no quadro e são vividas como uma ação corporal: de ingerir, devorar, guardar dentro de si. 0 termo identificação projetiva foi usado, pela primeira vez, por Melanie Klein, para designar uma forma especial de identificação que estabelece o protótipo de uma relação de objeto agressiva (Klein, 1947) - na posição esquizoparanóide -, representada por ataques ao interior do corpo materno, e de intrusão sádica nele, para lesar o corpo da mãe.

As ações sádico-masoquistas, na realidade, já haviam sido sublinhadas por Freud em "As Pulsões e suas Vicissitudes" (Freud, 1915/1972a), onde o sadismo é descrito como anterior ao masoquismo, sendo uma ação contra outrem, e o masoquismo correspondendo a uma volta da pulsão. Assim, a hostilidade contra os objetos que frustram transforma-se em hostilidade contra o próprio ego. O indivíduo se detesta porque há um desacordo entre o ego e o seu superego e, resultante disso, aparece o sentimento de culpa. Reich comparou os traços de caráter rígidos a uma armadura, que o ego enverga para se proteger tanto contra os instintos quanto contra os perigos externos, e "este caráter rígido será o resultado da colisão permanente entre as exigências instintivas e o ambiente frustrador ... e dos conflitos decorrentes entre o instinto e o ambiente deriva a sua força e o esforço tenaz à existência" (Reich, 1940 apud Fenichel, 1981, p.439). Há uma luta furiosa entre o superego e o objeto, como houve outrora entre o ego e o objeto. O desapontamento e a culpa se transformam no sentimento de autopunição: "não mereço viver". A instância crítica, responsável pelo castigo, é o superego que aqui está separado do ego, por clivagem, demonstrada por sua autonomia (Fenichel, 1981).

O superego, segundo a teoria kleiniana, é formado precocemente e dele derivam as fantasias inconscientes - estruturas fantásticas que surgem somente depois da primeira relação objetal -, que são as representações mentais das pulsões (Klein,1932). Essas fantasias podem tomar foro de realidade, como ocorre nos quadros psicóticos. Um paciente, com depressão melancólica, inicialmente desejava morrer porque havia perdido o prazer nas coisas do mundo. Os objetos pessoais, as pessoas da família, as casas, as árvores, as ruas de sua cidade pareciam mortos, sem vida. Posteriormente, essa sensação se estendeu para si mesmo, referida inicialmente como sensação de estranheza, de mal-estar físico e cansaço, depois pela angustiosa percepção da dissolução dos órgãos corporais internos e, finalmente, pela firme crença de que já estava morto, inabalável frente a qualquer argumento contrário.

\section{Mecanismos psicodinâmicos na depressão atípica}

O quadro da depressão atípica se avizinha dos quadros neuróticos, particularmente da histeria. Não foi por outro motivo que foi denominado, inicialmente, disforia histeróide. O principal receio do indivíduo, nesse caso, é perder o amor dos outros, ser abandonado. Esse subtipo de depressão se opõe ao da depressão melancólica, porque no primeiro há a presença de reatividade de humor, como condição sine qua non para o diagnóstico, e a ausência dela, para o diagnóstico da segunda.

Certa paciente apresentou o quadro logo após o término do namoro. Passou a se queixar de solidão, sonolência excessiva, permanecendo na cama várias horas por dia, alimentando-se de chocolates e deixando de lado todas as outras atividades consideradas prazerosas. Mas, quando atendia aos apelos de sua melhor amiga, depois de muita insistência, e a acompanhava ao cinema ou aos bares movimentados, sentia-se melhor do humor, participando com prazer de todas as atividades. Entretanto, ao retornar à sua casa, os sintomas reapareciam. Germaine Guex (apud Fenichel, 1981) descreveu, no século passado, um quadro muito semelhante a esse, a que denominou de neurose de abandono, no qual predominava a necessidade ilimitada de amor, como uma busca tenaz da segurança perdida (fusão primitiva da criança com a mãe). Freud trata desse assunto ao longo de toda a sua obra ao falar da sensação de desamparo que se observa em todas as idades, mas que se origina desde as primeiras relações estabelecidas pelo recém-nascido com a mãe (Gomes de Matos, 2000). A hiperfagia ocorre porque a pessoa se torna ávida e insaciável. Comer demais é um conflito pré-genital e deriva de um conflito materno pré-edipiano, que pode estar encoberto por um mecanismo sádico-oral, e ser um protesto contra a feminilidade e o ódio contra a mãe. Fome de provisões é, em última análise, a fome de amor. A ingestão de comida corresponde à ingestão inconsciente de 
provisões narcísicas, que abrandam a angústia, como um dia o leite materno representou a segurança para o bebê. Mas, exatamente porque falham esses mecanismos compensadores, a estabilidade desmorona e eclode o quadro depressivo com características atípicas. A fantasia inconsciente se expressa no mecanismo de regressão, que se instala. Uma parte preservada do ego se dedica aos cuidados da outra parte, a regredida, como a mãe que sente pena de um bebê desamparado. Sentir pena de si mesmo é o motivo que impulsiona o ego a desempenhar essa tarefa, e essa, por sua vez, está representada pelos cuidados consigo mesmo. As provisões narcísicas compreendem repouso (paralisia de chumbo), um bom sono reparador (hipersonia) e a alimentação excessiva, especialmente doces (hiperfagia), que culminam em ganho de peso. Mas, quando essa tarefa passa a ser desempenhada por outrem - no caso relatado acima, a amiga desempenha esse papel - o ego transfere temporariamente o seu trabalho, reassumindo-o tão logo o substituto se ausente (reatividade do humor). Aqui o comportamento suicida se resume, quase sempre, apenas à ideação e tentativas teatrais de suicídio, similarmente ao que acontece na histeria, ao contrário dos quadros depressivos melancólicos quando o suicídio muitas vezes se concretiza.

\section{Considerações Finais}

O principal ponto em comum entre a depressão melancólica e a depressão atípica é a perda - ou a ameaça da perda - do objeto amado; enquanto a principal diferença se refere à reatividade do humor. Na depressão melancólica o paciente não reage aos estímulos positivos que procedem do meio externo. Ao contrário, há uma tendência da piora do quadro pelo desenvolvimento ou agravamento subseqüente de idéias de culpa e de ruína. Na prática clínica, observa-se que o paciente sofre e se sente desmoralizado por não poder corresponder à expectativa dos parentes e amigos, que o estimulam a reagir. Isso faz aumentar, nele, a certeza de não merecer o amor dessas pessoas, bem como do afastamento e da perda desses objetos. A convicção que se abate é de tal ordem que podem surgir idéias delirantes. O isolamento do paciente e a sua impermeabilidade, ao meio externo, se solidificam e as manifestações de carinho e apreço não mais o atingem, culminando por dirimir qualquer esperança de vida. Os profissionais envolvidos no tratamento experimentam um difícil sentimento de impotência frente ao quadro.

Do ponto de vista psicodinâmico há uma regressão para fases muito primitivas, quando a separação da mãe foi sentida, pelo bebê, como uma sensação dolorosa e irreparável. Os sentimentos de raiva e de abandono foram tão intensos que eliminaram qualquer resquício de esperança. O protesto se tornou um registro indelével, que não possibilitou reparos posteriores. Figuras substitutas da mãe foram mal aceitas, ou recusadas por completo. O sentimento de não merecer perdão, pela raiva dirigida a essas pessoas, se traduz pelo desejo de punição e castigo. A depressão melancólica se expressa, assim, pela recusa alimentar, emagrecimento, isolamento, pessimismo, culpa excessiva e idéias de suicídio. O terapeuta, por sua vez, deve estar preparado para a difícil tarefa de lidar com as atitudes agressivas - de desafio e não colaboração - por parte do paciente, que estão a serviço de suas idéias pessimistas, que ele deseja confirmar, através do fracasso do tratamento.

Na depressão atípica, ao contrário, o paciente reage, ainda que temporariamente, aos estímulos externos positivos. A regressão, para fases anteriores do desenvolvimento, é menos profunda que no caso anterior. Por isso, a separação mãe-bebê trouxe conseqüências menos nefastas. Houve a aceitação de figuras substitutas, que se incorporaram como boas cuidadoras. Agora, a recepção afetiva é possível e bem-vinda. O afeto e os cuidados são aceitos com avidez. A representação simbólica desse movimento se manifesta pelo aumento do apetite e ganho de peso. Os alimentos doces, os preferidos na infância, passam a ser consumidos em excesso, numa tentativa dramática de compensarem a perda do(s) objeto(s) amado(s). A atitude colaborativa do depressivo atípico contrasta com as atitudes negativas do quadro melancólico. Entretanto, o terapeuta deve estar atento porque a fome de amor parece não se extinguir. Os períodos de melhora, pela reação aos estímulos, são seguidos por outros de piora e recaída. O paciente torna-se submisso e obediente, mas, ao mesmo tempo, dependente e infantilizado. Ele deixa de se autodeterminar, esperando que o terapeuta aja como uma mãe substituta em 
tempo integral, sempre presente para mitigar o seu desamparo, sua fome e orientar seus passos. A sua ausência, entretanto, é recebida com decepção e protesto, que se expressa pelo retorno ao leito, sonolência excessiva, ameaças de suicídio - geralmente apenas para despertar atenção - e recrudescimento do quadro.

A compreensão dos mecanismos psicodinâmicos, subjacentes à depressão melancólica - cuja moeda de troca é cunhada pela alteração do juízo da realidade, desesperança e (auto e hétero) agressividade - e à depressão atípica - pelo desamparo, dependência e voracidade oral -, são de grande importância para o trabalho do psicanalista, que não pode prescindir das modernas classificações psiquiátricas, surgidas nas últimas décadas, que trouxeram uma maior confiabilidade do diagnóstico e o desenvolvimento de estudos epidemiológicos mais acurados. Esforços que envolvam contribuições de ambas as áreas, psicanalítica e psiquiátrica, são necessários e bem-vindos para ampliar a eficácia do tratamento dessa patologia que tem se tornado uma grande preocupação de saúde pública, no nosso século, em virtude do aumento de sua prevalência, morbidade e mortalidade.

\section{Referências}

Birmaher, B., Ryan, N. D., \& Williamson, D. E. (1996). Childhood and adolescent depression: a review of the past 10-years. Journal American of Academy of Child and Adolescent Psychiatry, 35 (11), 1427-1439.

Classificação Internacional das Doenças (CID-10). (1993). Classificação de Transtornos Mentais e de Comportamento. Porto Alegre: Lemos.

Davidson, J. R. T., \& Meltzer-Brody, S. E. (1999). The underecognition and undertreatment of depression: what is the breath and deph of the problem? Journal of Clinical Psychiatry, 60 (24), 4-9.

Fenichel, O. (1981). Teoria psicanalítica das neuroses. Rio de Janeiro: Atheneu.

Frank, E., Prien, R. F., \& Jarret, R. B. (1991). Conceptualization and rationale to consensus definitions of terms in major depressive disorders: response, remission, recovery, relapse, and recurrence. Archives of General Psychiatry, 48 (9), 851-855.

Freud, S. (1972a). O instinto e suas vicissitudes. In Obras Completas de Sigmund Freud. Rio de Janeiro: Imago. (Originalmente publicado em 1915).
Freud, S. (1972b). Luto e melancolia. In Obras Completas de Sigmund Freud. Rio de Janeiro: Imago. (Originalmente publicado em 1917).

Friedman, R. A., \& Kocsis, J. H. (1996). Pharmacotheraphy for chronic depression. Psychiatry Clinical of North America, 19 (1), 121-132.

Gomes de Matos, E. (1999). A depressão e o clínico geral. Revista Brasileira de Clínica e Terapia, 25 (1), 12-15.

Gomes de Matos, E. (2000). Venlafaxina na depressão atípica. Jornal Brasileiro de Psiquiatria, 6, 185-191.

Greenberg, P. E., Stiglin, L. E., \& Finkelstein, S. N. (1993a). The economic burden of depression in 1990. Journal of Clinical Psychiatry, 54 (11), 405-419.

Greenberg, P. E., Stiglin, L. E., \& Finkelstein, S. N. (1993b). Depression: a neglected major illness. Journal of Clinical Psychiary, 54 (11), 419-424.

Kessler, L. G., Burns B. J., \& Shapiro, S. (1987). Psychiatric diagnoses of medical service users:evidence from the Epidemiologic Cathment Area Program. American Journal of Public Health, 77 (7), 18-24.

Kessler, R. C., McConagle, K. A., \& Zhoa, S. (1994). Lifetime and 12-month prevalence of DSM-III-R psychiatric disorders in the United States: results from the National Comorbidity Survey. Archives of General Psychiatry, 51 (1), 8-19.

Klein, M. (1932). Psicanálise da criança. São Paulo: Mestre Jou.

Klein, M. (1947). Contribuições à Psicanálise. São Paulo: Mestre Jou.

Kocsis, J. H. (2000). New strategies for treating chronic depression. Journal of Clinical Psychiatry, 61 (11), 42-45.

Laplanche, J., \& Pontalis, J. B. (1986). Vocabulário da psicanálise. São Paulo: Martins Fontes.

Manual Diagnóstico e Estatístico de Transtornos Mentais. (1995). (DSM-IV). Porto Alegre: Artes Médicas.

Murray, C. J. L., \& Lopez, A. D. (1996). A comprehensive assessment of mortality and disability from diseases, injuries, and the risk factors in 1990 and projected to 2020. Cambridge, Mass: Harvard University Press.

Pincus, H. A., \& Pettit, A. R. (2001). The societal costs of chronic major depression. Journal of Clinical Psychiary, 62 (6), 5-9.

Regier, D. A., Narrow, W. E., \& Rae, D. S. (1993). The de facto US mental and addictive disorders service system: epidemiologic catchment area prospective 1-year prevalence rates of disorders and services. Archives of General Psychiatry, 50 (2), 85-94.

Recebido em: 16/3/2005

Versão final reapresentada em: 27/9/2005

Aprovado em: 4/11/2005 
